\title{
Concept of application of the light-weight robot Robin Heart ("Pelikan") in veterinary medicine: a feasibility study
}

\author{
KRZYSZTOF LIS, KRZYSZTOF LEHRICH, ŁUKASZ MUCHA*, ZBIGNIEW NAWRAT*
}

Silesian University of Technology, Konarskiego 18a, 44-100 Gliwice, Poland

${ }^{*}$ Foundation of Cardiac Surgery Development, Biocybernetics Laboratory, Wolności 345a, 41-800 Zabrze, Poland

Lis K., Lehrich K., Mucha Ł., Nawrat Z.

\section{Concept of application of the light-weight robot Robin Heart (“Pelikan") in veterinary medicine: a feasibility study}

\section{Summary}

Currently, there is a great interest in the use of minimally invasive surgery methods. Such surgeries require special instrumentation. Doctors increasingly use medical robots that replace assistants responsible for setting the position and orientation of the endoscope (vision), as well as make it possible to control surgical instruments. One of very promising fields of expansion of this technology is veterinary medicine. This article presents a review of literature on animal laparoscopic surgery with the use of medical robots. Particular attention was paid to animal experiments involving the Robin Heart family robots. Moreover, the article presents the construction and principle of operation of the smallest manipulator of the Robin Heart family, as well as describes preliminary simulations of surgery with the use of this robot. In the conclusion, possible directions for further improvement and implementation of the Robin Heart robot have been formulated.

Keywords: Robin Heart Pelikan, robots in veterinary medicine, laparoscopic robot, camera-holding robotic device

The use of minimally invasive techniques, including laparoscopy, has become an alternative approach to the traditional laparotomy procedure used in the treatment of both humans and animals $(4,17)$. Laparoscopy has brought about significant changes in the world of surgery. Most important, it has eliminated the need for the large incision, which was once the only way to make the surgery field visible and accessible for a given procedure. The laparoscopic technique uses one (SILS surgery) or a few small incisions, through which surgical and optical instruments are inserted with the use of sealing ports (trocars). The introduction of the laparoscopic technique required the application of new tools (tools with long holding sections) as well as operating field visualization systems. During a surgery, the surgeon sees inside the patient via a screen, and the movements of the tool's end effector mirror the movements of the surgeon's hands. Additionally, in order to enlarge the operation field, gas is insufflated into the patient during the procedure, producing a pneumoperitoneum (6). With advantages, such as a shorter recovery time, reduced pain, excellent visualization of the abdominal cavity, and the possibility of being used not only in large animals (small-diameter tools), the laparoscopic technique is becoming increasingly popular in veterinary medicine, as well $(3,5)$. Continuous progress in medical technology stimulates the demand for highly specialized tools designed for a specific type of surgery. The increasing demand for high precision and the ever-growing possibilities of maneuvering the tools inside the patient's body have contributed to the introduction of robotic systems that support surgeons in the operating rooms. Robots equipped with laparoscopic tools have significantly shortened the duration of surgeries as well as improved their quality. The use of robots in veterinary surgery is in most cases limited to tests aimed at the clinical implementation of a given robot, tool, or procedure. Pigs have been the most commonly used animals in such experiments because of their anatomical features being similar to those of a human being. Pigs have provided a perfect cardiac surgery model necessary for comparative studies of laparoscopic and robotic surgery. Lomanto et al. (10) used the Zeus robot for cholecystectomy (a surgical removal of the gallbladder) in 7 pigs and, as their experience increased, 


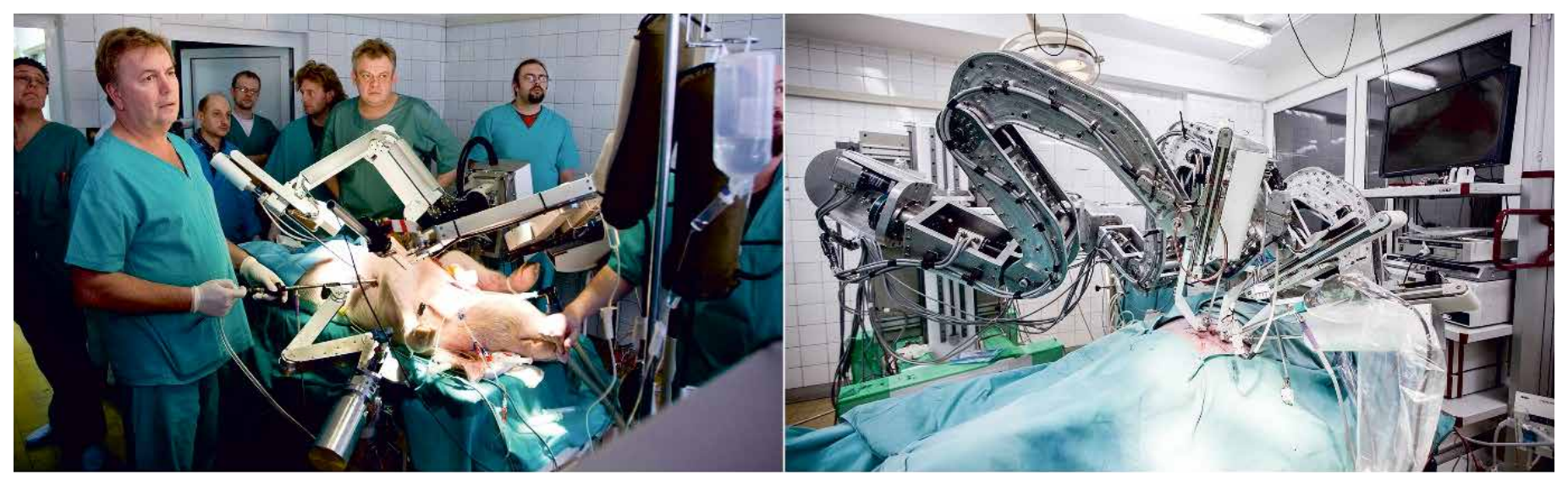

Fig. 1. Experiments with Robin Heart robots

they were able to reduce the time of surgery from 30 to 14 minutes. Zhu et al. (20) also tested a robot on pigs (Roux-en-Y). The operation with the use of the robot took longer than that with the use of traditional laparoscopic tools, but the efficiency of the surgery was satisfactory. Hollands et al. (7) also describe their short-term experiments with the use of the Zeus robot on pigs (enteroenterostomy - anastomosis between two parts of the small bowel; and choledochotomy removal of the common bile duct). They conclude that sewing the bile duct with a robot has more advantages than sewing it with typical laparoscopic tools. Further experiments involving hepatectomy (liver resection) were conducted by J. Leroy (15) on 15 pigs and demonstrated the suitability of the Zeus robot for dissection and ligation of vessels in the liver. Margossian et al. (11) in their work describe a robot-assisted uterine horn anastomosis in a pig. Further experiments involving the Zeus robot were carried out in the field of pyeloplasty (renal pelvis surgery), nephrectomy (removal of the kidney), and adrenalectomy (removal of adrenal glands). Boehm et al. (1) report that in early robotic cardiac surgery examinations, a laboratory model with pigs' hearts was used (109 anastomoses of the coronary artery - LAD in total), followed by six experiments on dogs (the internal thoracic artery - „LIMA to LAD”). Ruurda et al. (16) examined the effectiveness of the da Vinci robot in circulatory anastomoses on 30 pigs, 20 of which were performed laparoscopically and 10, for comparison, by laparotomy. Laparoscopic surgery took longer, but the mechanical quality of the seams was good, as verified after 14 days. A significant advantage of using robots in the operating room is the ability to perform surgeries at a distance (remote surgery). In this manner, the procedure was performed with the da Vinci robot on 4 pigs. The surgeon and the patients were separated by distances of 1,300 and 2,400 miles. The signal delay (the decisive factor in determining whether a teleoperation can be performed) was 450-900 ms, which was short enough for such an operation to be possible (19). Bowersox and his team tested robots for invasive cardiology in six experiments on pigs, using a robot called CardioArm.
Epicardial ablation was performed on a beating pig heart with substernal access (the xiphoid process of the sternum) (2). In 2015, an Italian medical team led by Giuliano Ravasio performed the world's first adrenal tumour surgery on an eight-year-old lion with the use of a robot. Thanks to the use the Telelap ALF-X robot and the laparoscopic technique, the lion was able to walk within 3 hours of the operation, and after 24 hours it was back home (http://totallycoolpix.com/ magazine/2015/05/robot-performs-surgery-on-a-lion, 15 September 2016). In Poland, a team led by Zbigniew Nawrat performed the first experiments on animals (pigs), a gallbladder surgery, valve surgery (mitral), and coronary artery bypass grafting, at the Centre for Experimental Medicine, Medical University of Silesia in Katowice (Fig. 1) (14). All these procedures confirm the feasibility and validity of using robotic systems in operating rooms.

\section{Robin Heart "Pelikan" Project}

Robots in the operating room can perform a specific medical procedure or "assist" the surgeon during a surgery, for example by holding the laparoscopic camera. Replacement of a person holding the laparoscope with an automated system (a robot) reduces the cost of treatment as well as significantly increases the availability of the necessary staff, especially in emergency situations $(8,14)$. To meet the expectations of veterinary physicians, a team of researchers from the Cardiac Surgery Development Foundation and the Silesian University of Technology decided to assess the applicability of the Robin Heart "Pelikan" robot in veterinary procedures performed on animals. For the purpose of the project, a special support frame was made to mount the robot on a standard operating table and to pre-position it conveniently for the patient and the operating surgeon. The Robin Heart "Pelikan" is a vision tracking robot that has 4 degrees of freedom (DOF 4) enabling it to navigate the camera inside the abdominal cavity. DOF 1 and 2 make it possible to change the position of the robot (tilting front-back and left-right), while DOF 3 and 4 are responsible for rotating the camera and for pulling it forward and backward. 

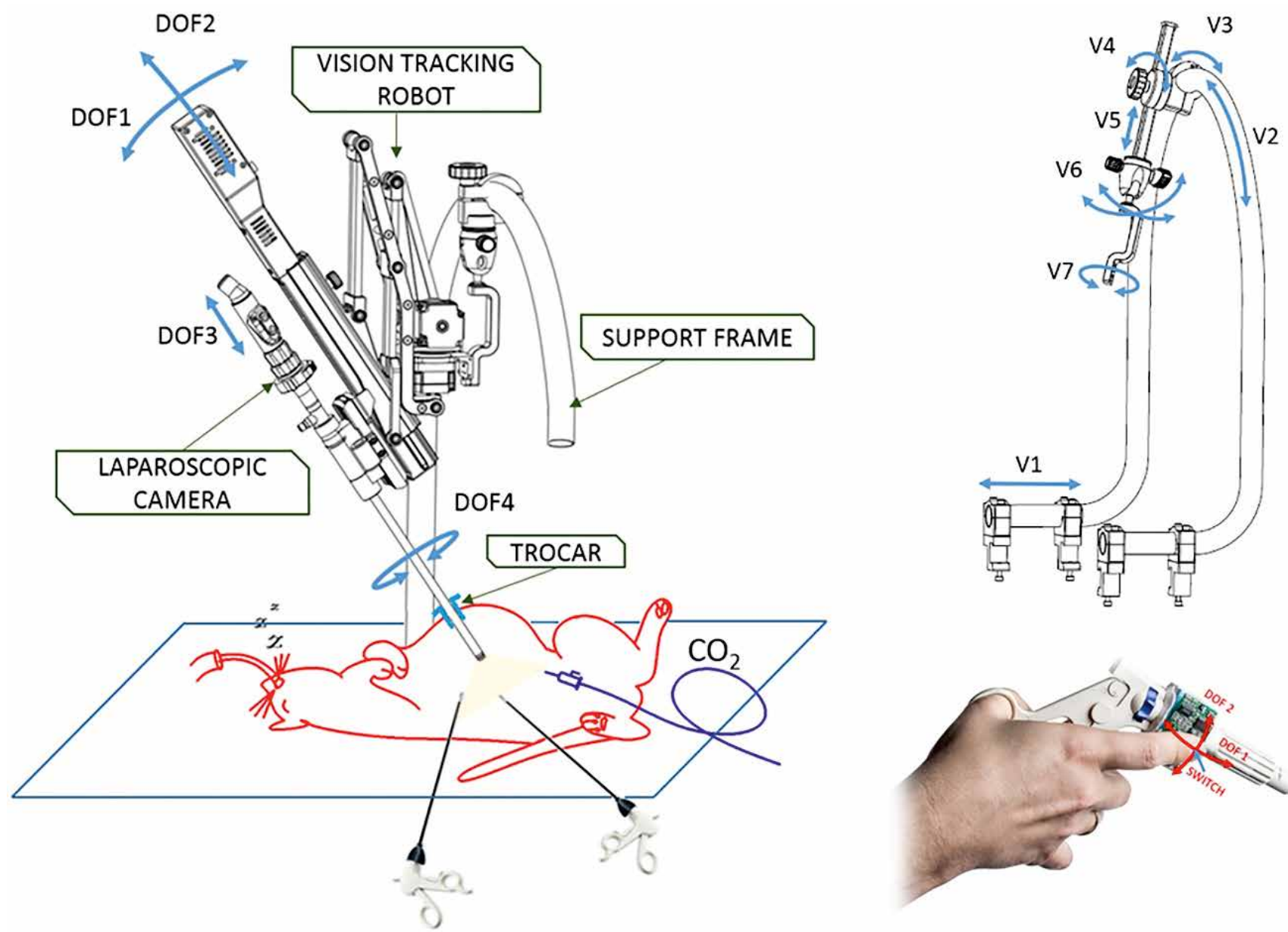

Fig. 2. The application concept for the "Pelikan" surgical robot in veterinary medicine and the supporting frame manipulation directions

This robot has a mechanical constant fixed position at the camera's entrance port on the patient's skin. Composite materials made it possible to minimize the weight of the robot (which is approx. $4 \mathrm{~kg}$ ), permitting transportation in a small suitcase. With this solution, the robot can be transported to another clinic or operating room in a short time (9). Steering the robot is done with a manipulator mounted directly on a traditional laparoscopic tool. The surgeon uses the index finger to exert pressure on a force sensor. This solution makes it possible to freely manipulate the robot without putting away the tools held in hand. Figure 2 shows the robot's degrees of freedom, the mounting system (the supporting frame) adjustment, and the steering system options (direction controller) $(7,13)$.

By applying numerical methods, the manipulation space for a laparoscopic camera inside the CAD model of a dog was designated, thus identifying the field of view defined by the cone (Fig. 3). The simulations performed made it possible to visualize the observed space and to formulate a preliminary plan of treatment. Setting the robot on the supporting frame in a way that would not limit the movements of the operating surgeon was one of the issues considered.

In surgery, robots are used to manipulate tools such as endoscopic optical instruments and/or endoscopic surgical instruments. The Robin Heart "Pelikan" project responds to the needs of the medical world for a lightweight, portable robotic device to control the position of an endoscopic camera. The task of designing a robot which, on the one hand, is precise enough, and on the other, easily transported and mounted in a standard operating room is primarily a technological and construction design challenge. As part of the Robin Heart surgical robot tests, a series of 3 experiments on animals (pigs) was carried out as well as a remote surgery (an anatomical model of a human with a pig heart) at the Centre for Experimental Medicine, Medical University of Silesia in Katowice. There have been a number of important tests of several models of Robin Heart robots, and the conclusions have been used to improve them before the planned implementation. Laboratory, technical and ergonomic tests have made it possible to verify and improve the Robin Heart telemanipulator. Successive versions of the Robin Heart robots, including Robin Heart "Pelikan", are currently in a testing phase aimed at preparing them for clinical trial implementation. It is expected that further work on the "Pelikan" robot will improve the prototype, leading to certification and clinical trials. Further efforts will focus on preparing the robot for production and clinical implementation. 


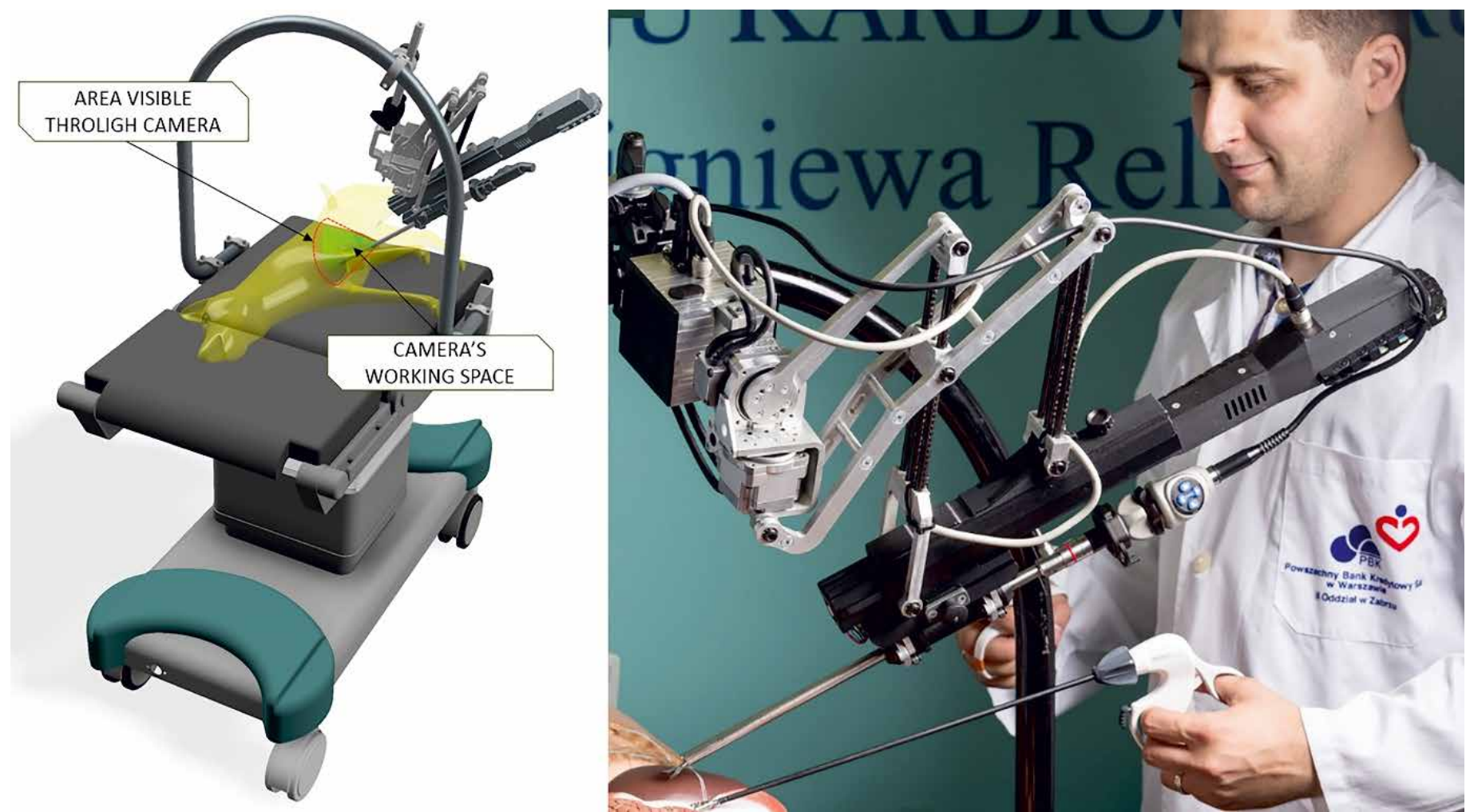

Fig. 3. Robin Heart "Pelikan" Robot: CAD model showing the manipulation space and a real-life model mounted on an operating table

\section{References}

1. Boehm D. H., Reichenspurner H., Gulbins H., Detter C., Meiser B., Brenner P. Habazettl H., Reichart B.: Early experience with robotic technology for coronary artery surgery. Ann. Thorac. Surg. 1999, 68, 1542-1546.

2. Bowersox J. C., Shah A., Jensen J., Hill J., Cordts P. R., Green P. S.: Vascular applications of telepresence surgery: initial feasibility studies in swine. J. Vasc. Surg. 1996, 23, 281-287.

3. Cosford K. L., Shmon C. L., Myers S. L., Taylor S. M., Carr A. P., Steiner J. M., Suchodolski J. S., Prospective F.: Evaluation of Laparoscopic Pancreatic Biopsies in 11 Healthy Cats. Mantovani, J. Vet. Intern. Med. 2010, 24, 1, $104-$ -113 .

4.Davidson E. B., Moll H. D., Payton M. E.: Comparison of laparoscopic ovariohysterectomy and ovariohysterectomy in dogs. Vet. Surgery 2014, 33 , 62-69.

5. Devitt C. M., Cox R. E., Hailey J. J.: Duration, Complication, Stress and Pain of Open Ovariohysterectomy Versus a Simple Method of Laparoscopic-Assisted Ovariohysterectomy in Dogs. J. Am. Vet. Med. Ass. 2005, 227, 921-928.

6. Fransson B. A., Mayhew P. D.: Small Animal Laparoscopy and Thoracoscopy. Chichester, West Sussex; Ames, Iowa: Wiley-Blackwell 2015.

7.Hollands C. M., Dixey N., Torma M. J.: Technical assessment of porcine enteroenterostomy performed with Zeus robotic technology. J. Pediatr. Surg. 2001, 36, 1231-1233.

8. Lanfranco A. R., Castellanos A. E., Desai J. P., Meyers W. C.: Robotic surgery: a current perspective. Anim. Surgery 2004, 239, 14-21.

9. Lehrich K., Mucha E., Rohr K., Nawrat Z., Lis K.: Zastosowanie technologii druku 3D w konstrukcji prototypów manipulatorów medycznych. Mechanik 2016, 3, 224-225.

10. Lomanto D., Cheah W. K., So J. B., Goh P. M.: Robotically assisted laparoscopic cholecystectomy: a pilot study. Arch. Surg. 2001, 136, 1106-1108.

11. Margossian H., Garcia-Ruiz A., Falcone T., Goldberg J. M., Attaran M., Gagner M.: Robotically assisted laparoscopic microsurgical uterine horn anastomosis. Fertil. Steril. 1998, 70, 530-534.

12. Mucha $E .:$ Interfejs użytkownika robota - przegląd urządzeń zadawania ruchu systemów sterowania telemanipulatorów. Medical Robotics Reports 2015, 4 , 39-48.

13. Nawrat Z., Rohr K., Fürjes P., Mucha Ł., Lis K., Radó J., Dücsö C., Földesy P., Sadowski W., Krawczyk D., Kroczek P., Szebényi G., Soósd P., Małota Z: Force Feedback Control System Dedicated for Robin Heart Surgical Robot. 30th Eurosensors Conference, EUROSENSORS 2016, Proc. Engineering, Budapest 2016, 00, 1-5.
14. Religa G., Zembala M., Cichoń R., Nawrat N., Kostka P., Dybka W., Rohr K., Podsędkowski L., Śliwka.: Pierwsze eksperymenty na zwierzętach robota chirurgicznego Robin Heart. Pomiary Automatyka Robotyka 2010, 2, 539-545.

15. Rubino F., Nahouraii R., Deutsch H., King W., Inabnet W. B., Gagner M.: Endoscopic approach for carotid artery surgery. Surg. Endosc. 2002, 16, 789 $-794$.

16. Ruurda J. P., Broeders I. A.: Robot-assisted laparoscopic intestinal anastomosis Surg. Endosc. 2003, 17, 236-241.

17. Schippers E., Tittel A., Ottinger A., Schumpelick V.: Laparoscopy versus laparotomy: comparison of adhesion-formation after bowel resection in a canine model. Dig. Surg. 1998, 15, 145-147.

18. Sterbis J. R., Hanly E. J., Herman B. C., Marohn M. R., Broderick T. J., Shih S. P., Harnett B., Doarn C., Schenkman N. S.: Transcontinental telesurgical nephrectomy using the da Vinci robot in a porcine model. Urology 2008, 71, 971-973.

19.Zhu J. F., Nahouraii R., Rubino F., Pamoukian V. N., Gagner M.: Roboticassisted laparoscopic cholecystojejunostomy. Minim. Invasive Ther. Allied Technol. 2001, 10, 83-88.

Corresponding author: dr inż. Krzysztof Lis, Wilkowice, ul. Wąska 3e, 42-674 Zbrosławice; e-mail: krzysztof.lis@polsl.pl 